\title{
AS FAKE NEWS NA ERA digital E A AUSÊnCIA de POLÍticas PÚbliCAS DE EDUCAÇÃO PARA O USO DAS TICS ${ }^{1}$
}

\author{
FAKE NEWS IN DIGITAL AGE AND THE ABSENSE OF PUBLIC POLICIES OF
}

EDUCATION FOR THE USE OF ICT'S

\author{
Charles Emmanuel Parchen ${ }^{2}$ \\ Cinthia Oblande de Almendra Freitas ${ }^{3}$ \\ Tássia Teixeira de F.B.E Cavalli ${ }^{4}$
}

\begin{abstract}
Resumo: Pelo método indutivo e pelo procedimento da coleta empírica de dados e com apoio da revisão bibliográfica, da pesquisa exploratória e descritiva, o estudo objetiva discutir a prática das denominadas Fake News no ambiente político e digital brasileiro, para alertar acerca da necessidade de adoção de políticas públicas governamentais que priorizem a educação para o uso das tecnologias, pois é na ausência de educação para o uso das tecnologias das TICs que as Fake News encontram um cenário ideal para se propagar. Conclui o artigo que a educação para o uso das tecnologias como política pública é a forma mais eficiente de se atender ao princípio da dignidade da pessoa humana e também de promoção dos direitos fundamentais de liberdade individual, pois só assim haverá a ocorrência da verdadeira inclusão digital, alcançada com a emancipação do ser humano através do processo educacional.
\end{abstract}

Palavras-Chave: Fake News; Era digital; Políticas públicas; Educação; Tecnologia

Abstract: Applying inductive method and by the procedure of empirical data collection from
secure sources and with support from literature review, exploratory and descriptive research,
the paper discusses the practice called the Fake News, in the Brazilian political and digital
environment, to alert about the need to adopt governmental public policies that prioritize

\footnotetext{
${ }^{1}$ Artigo submetido em 16/08/2018 e aprovado para publicação em 15/06/2020.

2 Doutor em Direito Econômico e Socioambiental pela PUC/PR (2020). Mestre em Direito Econômico e Socioambiental pela PUC/PR (2014). Especialista em Direito Privado pela Universidade Gama Filho-RJ (2009). Especialista em Processo Civil pela PUC-PR (2005). Bacharel em Direito pelo Centro Universitário CuritibaUnicuritiba/PR (2003). Professor do curso de Direito do Centro Universitário Curitiba-Unicuritiba/PR. Professor do Curso de Administração de empresas e Engenharia Civil do Unicuritiba/PR. Professor convidado da pós-graduação na Academia Brasileira de Direito Constitucional - ABDConst/PR. Membro titular da Comissão de Direito do Consumidor da OAB/PR. Advogado em escritório próprio de advocacia, com atuação no consultivo e litigioso empresarial, na área cível e do consumidor. Tem experiência na área de Direito, com ênfase em Direitos e Novas Tecnologias, Direito Socioambiental, Direito Civil, Processual Civil, Consumidor e Família. ORCID: https://orcid.org/0000-0003-0596-3212.

${ }^{3}$ Doutora em Informática pela Pontifícia Universidade Católica do Paraná. Professora Titular da PUC/PR da Escola de Direito. Professora Permanente do Programa de Pós-Graduação em Direito Econômico e Socioambiental da PUC/PR. E-mail: cinthia@ppgia.pucpr.br. ORCID: https://orcid.org/0000-0002-7015-094X ${ }^{4}$ Doutoranda do Programa de Pós-Graduação em Direito da PUC/PR. Mestre em Direito Econômico e Socioambiental pela PUC/PR- Pontifícia Universidade Católica do Paraná e Doutoranda em Direito Socioambiental e Sustentabilidade pela PUC/PR. Professora de Direito. Advogada. EMail: tassia_erbano@yahoo.com.br. ORCID: https://orcid.org/0000-0003-1526-7907.
} 
education for the use of technologies, because it is in the absence of education for the use of ICT technologies that Fake News find an ideal scenario to spread. The paper concludes that education for the use of technologies as public policy is the most efficient way to comply with the principle of the dignity of the human person and also to promote the fundamental rights of individual freedom, since only then will there be the occurrence of true digital inclusion, achieved with the emancipation of the human being through the educational process.

Keywords: Fake News; Digital era; Public policies; Education; Technology

\section{Introdução}

Segundo a última Pesquisa Nacional por Amostra de Domicílios (PNAD Contínua) realizada e divulgada pelo IBGE no ano de 2018 para verificação do acesso à Internet e à televisão e posse de telefone móvel celular para uso pessoal, no Brasil havia 181.869.000 de pessoas com 10 anos ou mais de idade. Destes, 74,7\%, ou seja, 135.908.000 de pessoas havia usado a Internet no quarto trimestre do ano de 2018 (IBGE, 2018, p.1).

Já para o ano de 2019, o Centro Regional de Estudos para o Desenvolvimento da Sociedade da Informação (CETIC) demonstrou que 50.696.007 de domicílios permanentes tem acesso à Internet, seja em aparelhos celulares, microcomputadores ou outros dispositivos tecnológicos. Por sua vez, dados dos estudos mostram que 65.992.169 domicílios brasileiros possuem telefone celular, 11.484 .971 computador de mesa, 18.500.163 computador portátil e 9.198.215, tablet (CETIC.BR, 2019, p.1).

O grande número de pessoas utilizando dispositivos tecnológicos com conexão à rede mundial de computadores pode ser explicado, em grande parte, por intermédio das políticas públicas de renúncia fiscal que suspenderam a incidência de impostos (principalmente PIS/Pasep e COFINS) aos fabricantes, importadores e exportadores de tecnologia, e que culminaram na criação da Lei 11.196/2005.

Referida legislação, conhecida como "Lei do Bem" é, na visão de Humberto Barbato, Presidente da Associação Brasileira da Indústria Elétrica e Eletrônica - Abinee na gestão 2015-2018, relacionada como uma grande força motriz da inclusão digital brasileira:

\footnotetext{
Além do combate ao mercado informal, a Lei do Bem também tem sido essencial para o programa de inclusão digital do governo, que, embora bem-sucedido até aqui, ainda tem muito a avançar, principalmente, considerando todas as oportunidades que surgem no horizonte próximo, com a internet das coisas, onde a tecnologia estará cada vez mais presente na vida de toda a sociedade (ABINEE, 2015, p.1).
} 
Tais ações foram sucessivamente prorrogadas ao longo dos anos, principalmente em 2014, quando o Governo Federal concedeu isenção de PIS e COFINS também aos comerciantes de computadores, smartphones, tablets e roteadores (O GLOBO, 2014, p.1). Importante frisar que tais benefícios foram retirados no ano seguinte, por intermédio da Medida Provisória $n^{\circ} 690$.

Portanto, os indicadores anteriormente relacionados e também este panorama de políticas públicas serve a demonstrar que é indubitável o espraiamento da tecnologia nos lares brasileiros e sua maciça utilização. Ocorre que a propagação de aparatos tecnológicos não se fez acompanhar - em velocidade compatível - da necessária educação para uso.

Desta forma, a falta de um conhecimento razoável sobre as tecnologias cotidianas e os riscos a elas relacionados repercute em negativos efeitos socioambientais que acabam sendo suportados de forma direta ou indireta por toda a sociedade, pois é justamente na ausência de um processo educacional preocupado com a inserção e interação socioambiental entre o Humano e a tecnologia, é que acaba se verificando um generalizado mau comportamento do usuário da tecnologia, que não se encontra plenamente consciente de seu papel na construção e promoção de uma cibercidadania, ou seja, de "uma consciência coletiva, livre, protegida e universal que desestimule a adoção de comportamentos perniciosos ou ilegais" (TAPSCOTT, 2000, p.357).

Neste complexo cenário digital que alia o vazio educacional à alta insegurança em relação ao comportamento do usuário diante do uso das TICs, encontra-se a forte incidência das denominadas Fake News, ou notícias falsas veiculadas na Internet que, pelos seus efeitos, são graves o suficiente a justificar o tema do presente estudo e, portanto, sua análise mais aprofundada.

A razão maior pela qual se entende que o presente trabalho é relevante reside justamente no fato de que se pretende demonstrar que o processo de educação para o uso das TICs, a despeito das tentativas de Nações e governos de multar empresas que divulgam e não controlam as Fake News, é o único caminho apto a privilegiar a já consolidada legislação em vigor, até como forma de permitir a construção salutar da mencionada cibercidadania e, também promover um ambiente digital que seja desenvolvido, mas ao mesmo tempo, sustentável.

Importa esclarecer que o presente artigo (de forma propositada e até porque justamente seu escopo é a análise do fenômeno das Fake News veiculadas pela Internet) 
utilizará precipuamente como fontes de seu embasamento, notícias veiculadas na rede mundial de computadores.

Para tanto e, justamente, com o intuito de evitar ser mais uma vítima daquilo que delineia (falsas notícias), todas as informações retiradas da Internet passaram pelos seguintes critérios: 1) somente foram utilizadas notícias de sites de organizações e empresas tradicionais e consagradas no mercado nacional e internacional, preferencialmente aquelas que contêm corpo de jornalistas e uma redação organizada por editores e chefias; 2) independentemente deste critério anterior, só foram utilizadas no artigo, notícias que puderam ser checadas em mais de uma fonte confiável, ou seja, que apareciam na mesma época em outros meios consagrados e tradicionais de divulgação; 3) informações constantes das notícias, tais como referências a organizações, estudos e relatórios, foram checadas em suas fontes originais na Internet, e aquelas cujas fontes originais não foram localizadas ou eram dúbias, ficaram fora do escopo da pesquisa; 4) como regra, foram usadas as fontes originais de dados estatísticos, tabelas e relatórios.

Desta forma, este conjunto de critérios foi eficaz para evitar a ocorrência e perpetuação de Fake News por meio deste artigo. É importante notar que ninguém está livre de se sujeitar à uma notícia falsa, ainda mais o pesquisador que necessita de inúmeras informações contextuais e utiliza os benefícios e facilidades da Internet para compor sua base de dados.

Como é proposição final do texto asseverar a necessidade da educação para o bom e correto uso das tecnologias como forma de se evitar a ocorrência e perpetuação de Fake News que assolam a sociedade digital, se o presente estudo não tivesse como tônica em sua redação a preocupação constante com tais posturas, certamente haveria uma incongruência lógica difícil de ser superada.

O estudo tem por objetivo trazer à discussão a deletéria prática das denominadas Fake News no ambiente digital brasileiro para, em momento posterior, alertar acerca da necessidade de adoção de políticas públicas governamentais que priorizem a educação para o uso das tecnologias ao invés de impor meras sanções pecuniárias às pessoas ou empresas que disseminem falsas notícias. Isso porque, na ótico do artigo, embora haja diversas explicações para a ocorrência das notícias falsas, a principal delas é a ausência de digital literacy, ou seja, de habilidades sociais elementares para se viver em sociedade informacional.

Com isto, o resultado esperado é de que seja possível ao leitor perceber que em todos os aspectos da vida digital cotidiana é premente a adoção de uma postura ativa, 
consciente, neutra, livre e, principalmente, acautelatória, o que só se alcança com um mínimo grau de instrução e conscientização do problema das Fake News.

Usando do método indutivo e por intermédio do procedimento da coleta empírica de dados em fontes seguras da Internet e também com auxílio secundário da revisão bibliográfica e de pesquisa exploratória e descritiva, o presente estudo traz como hipótese a afirmação de que as notícias falsas veiculadas na Internet são causadas, precipuamente, pela ausência de educação para o correto uso das TICs. Aponta-se, no item 2, a incidência do analfabestimo digital que assola o Brasil, trazendo dados estatísticos sobre a vulnerabilidade na qual se encontra inserido o usuário da tecnologia. Neste contexto, são abordadas as Fake News em seu conceito e principais características.

O item 3 trata da necessidade de adoção de políticas públicas de educação para o uso da TICs como eficaz ferramenta de combate à incidência das notícias falsas na Internet. Conclui o texto que a educação para o uso das tecnologias como política pública é a forma mais eficiente de se atender ao princípio da dignidade da pessoa humana e também de promover os direitos fundamentais de liberdade individual, pois só assim haverá a ocorrência da verdadeira inclusão digital, alcançada somente com a premente emancipação do ser humano que se dá por meio do processo educacional, único intrumento apto para que haja a internalização e replicação do conhecimento.

\section{O Analfabetismo Digital Brasileiro}

É possível afirmar que a sociedade brasileira não foi educada para o uso das TICs e, portanto, não está totalmente consciente dos riscos a que está submetida quando o assunto é a era digital. Sobre a não assunção dos riscos, assevera Ulrich Beck:

Riesgo es el enfoque moderno de la previsión y control de las consecuencias futuras de la acción humana, las diversas consecuencias no deseadas de la modernización radicalizada. Es un intento (institucionalizado) de colonizar el futuro, un mapa cognitivo. Toda sociedad, por supuesto, ha experimentado peligros. Pero el régimen de riesgo es una función de un orden nuevo: nos es nacional, sino global. Está íntimamente relacionado con el proceso administrativo y técnico de decisión (BECK, 1999, p.5). ${ }^{5}$

\footnotetext{
${ }^{5}$ Tradução livre: Risco é o enfoque moderno da previsão e controle das consequências futuras da ação humana, as diversas consequências não desejadas da modernização radical. É um intento (institucionalizado) de colonizar o futuro, um mapa cognitivo. Toda sociedade, por óbvio, tem experimentado perigos. Mas o regime do risco é uma função de uma nova ordem: não é nacional, senão global. Está intimamente relacionado com o processo administrativo e técnico de decisão.
} 
Os indicadores trazidos no presente estudo pretendem demonstrar isto. O fato é que, como não há uma educação para o correto uso das tecnologias, inúmeros maus hábitos sociais podem ser verificados contemporaneamente no ambiente digital.

Como alguns exemplos, podem ser citados os discursos de ódio (hatterismo), os crimes de aliciamento sexual baseados na Internet, a perda da privacidade e intimidade ocasionada por "vingança pornô" (ou porno revanche: exposição dolosa e indevida de conteúdo íntimo na rede mundial de computadores, geralmente por conta do término de um relacionamento amoroso), o cyberbullying e os golpes relacionados a furto de dados de cartão de crédito e senhas de acesso bancário quando ocorre instalação de softwares maliciosos ou vírus de computador, e ainda, a trollagem. ${ }^{6}$

A respeito desta última prática é interessante destacar o fato de que os internautas brasileiros são bastante conhecidos em comunidades virtuais internacionais por seus discursos agressivos, inconvenientes e antissociais (PORTAL UOL, 2014, p.1). Destaque-se que, por necessidade de um corte epistemológico, nenhuma destas práticas acima nominadas será abordada no presente estudo.

Logo, denota-se que a ausência de educação para o uso das tecnologias faz surgir e propagar os denominados "analfabetos digitais", ou seja, pessoas que, por não saberem usar corretamente as tecnologias - já que não tem a necessária instrução para tal - acabam sendo o vetor de maus comportamentos, espalhando e sofrendo toda a carga de pesados efeitos negativos decorrentes de seus atos:

\begin{abstract}
Em todo o mundo, a modernização das sociedades, o desenvolvimento tecnológico, a ampliação da participação social e política colocam demandas cada vez maiores com relação às habilidades de leitura e escrita. A questão não é mais apenas saber se as pessoas sabem ou não ler e escrever, mas também o que elas são capazes ou não de fazer com essas habilidades. Isso quer dizer que, além da preocupação com o analfabetismo, problema que ainda persiste nos países mais pobres e também no Brasil, emerge a preocupação com o alfabetismo, ou seja, com as capacidades e usos efetivos da leitura e escrita nas diferentes esferas da vida social. Ocorre que aquele que não domina a informática é um verdadeiro analfabeto, marginalizado pela rápida evolução tecnológica que possibilita $\mathrm{o}$ acesso à informação. $\mathrm{O}$ analfabetismo digital é um grande fator de exclusão, que resulta em sérias implicações sociais, políticas, jurídicas e econômicas. Antes se falava que aquele que não fosse devidamente alfabetizado, que não conseguisse interpretar e compreender um texto, estava marginalizado, estigmatizado. Com esteio nesta assertiva, essa tal pessoa não teria sua cidadania exercida plenamente, estando, pois, fadada inexoravelmente a um destino sem perspectivas, restando-lhe somente
\end{abstract}

\footnotetext{
${ }^{6}$ A trollagem consiste basicamente no fato de alguém tumultuar propositadamente e, utilizando-se de argumentos estúpidos, alguma discussão na Internet, ou ainda, praticar brincadeiras ou "pegadinhas" de forma a induzir as pessoas em erro e também a passar por situações constrangedoras e engraçadas perante as vistas de todos na Internet. $\mathrm{O}$ termo advém do troll, criatura mítica e lendária que era caracterizada por sua agressividade e falta de inteligência.
} 
subempregos. Com efeito, a exclusão agora é outra. Hoje, "navegar" é imprescindível, sobretudo, dominar as tecnologias de informação. Sem embargos, informação é poder. Diante de tais circunstâncias, o já estreito funil da exclusão ficou mais apertado. É de incontroverso saber que a Internet e o computador são ferramentas imprescindíveis para quem quer se inserir no mercado de trabalho. Isto porque, desde o balconista do supermercado até o dentista ou o advogado, a todos se impõe o uso da informática. Qualquer profissional precisa dominar as tecnologias de informação, seja ele quem for, esteja ele onde estiver. Hodiernamente, sem informação não há comunicação, o que resulta em exclusão, marginalização... Temos, então o surgimento do excluído digital, o marginalizado do século XXI (MALAQUIAS, 2003, p.1). ${ }^{7}$

Disto decorre que, para Bruno Pires Malaquias, é possível hodiernamente se falar em "párias" ou "marginalizados" do século XXI. Corroborando as nefastas consequências desta afirmação, o relatório do ano de 2016 da empresa Symantec, uma das líderes em segurança da informação digital, aponta que no Brasil, 42,4 milhões de consumidores foram afetados pelo cybercrime, sendo que os mais comuns são o comprometimento de senhas de contas (22\%), bem como e-mails hackeados (17\%) (SYMANTEC, 2016, p.1).

Do mesmo relatório se depreende que, enquanto a nível global 30\% dos consumidores não conseguem identificar um ataque de phishing ${ }^{8}$, o percentual de brasileiros que não os conseguem identificar é bem maior: 44\%. Já a amostra daqueles que usa ao menos um dispositivo desprotegido no Brasil é de $37 \%$, enquanto que no resto do mundo é de $35 \%$ (SYMANTEC, 2016, p.1).

A consequência disto é o aumento dos ataques cibernéticos visando, por exemplo, o pagamento de valores pecuniários para que haja a devolução de dados "sequestrados". Estudo da referida empresa mostra que o Brasil foi o $11^{\circ}$ país mais afetado no mundo pelo ataque, no ano de 2017, de ransomware de furto de credenciais chamado "Petya" (O'BRIEN, 2017, p.1). O mesmo relatório assevera o potencial econômico danoso de ataques cibernéticos: "The average ransom demand seen in new ransomware families appears to have stabilized at US\$544 indicating attackers may have found their sweet spot" ${ }^{9}$ (O’BRIEN, 2017 p.4).

É interessante notar que todos estes tipos de práticas sociais na Internet geralmente acontecem porque pessoas clicam em links indevidos, instalam software escusos sem antes

\footnotetext{
${ }^{7}$ Importante destacar que não é escopo do presente artigo abordar a questão dos chamados "info-excluídos", ou seja, aqueles que, por diversos motivos, não tem acesso à tecnologia.

8 Phishing é a prática de "coleta" ou "pesca" de dados pessoais em dispositivos eletrônicos que pode levar até mesmo a destruição de arquivos sensíveis ou ter como consequência, o "sequestro" de dados mediante o pagamento de um "resgate" (ransomware).

9 Tradução livre: "A demanda média de resgate encontrada nas novas versões de ransomware parece ter estabilizado em US\$ 544, indicando que os atacantes podem ter encontrado o seu ponto ideal”.
} 
verificar sua idoneidade e acreditam em informações que induzem à falsa crença de segurança e credibilidade do que lhe é apresentado.

Uma reportagem de mídia traz a importante informação de que o Brasil é considerado o $6^{\circ}$ mais vulnerável país do mundo à ataques cibernéticos, simplesmente porque não há investimento em segurança de dados pessoais e sensíveis, como ocorre quando se adquire um software antivírus, por exemplo (O GLOBO, 2017, p.1).

Logo, é possível perceber de antemão que todas estas consequências são, em grande parte, causadas e explicadas pelo mau comportamento de usuários das tecnologias que, por não terem a devida instrução acerca do correto uso das mesmas, acabam potencializando a sua vulnerabilidade quanto estão diante do ambiente fluído, instantâneo e imediato da era digital.

Ocorre que dentre as práticas verificadas no ambiente digital - sendo que algumas delas foram nominadas anteriormente - encontra-se uma que será objeto de análise do presente texto, porque causa especial preocupação por sua relevância, gravidade e poder de impacto global: são as chamadas Fake News (notícias falsas) de Internet.

As Fake News, embora haja uma complexidade de fatores que contribuem para sua ocorrência, na proposição do presente artigo são causadas precipuamente por falta de acurácia ou destreza digital (digital literacy). Este termo pode ser conceituado como: “Digital literacy means having the skills you need to live, learn, and work in a society where communication and access to information is increasingly through digital technologies like internet platforms, social media, and mobile devices" ${ }^{\prime 10}$ (WESTERN SYDNEY UNIVERSITY, [2016?], p.1).

Por sua vez, o autor Richard Lanham, apud Colin Laskshear e Michele Knobel (2006, p.12) designa digital literacy como: "the ability to understand information however presented" $"$. A expressão pode ser entendida como:

To be digitally literate is to have access to a broad range of practices and cultural resources that you are able to apply to digital tools. It is the ability to make, represent and share meaning in different modes and formats; to create, collaborate and communicate effectively and to understand how and when digital technologies can best be used to support these processes (PAYTON; HAGUE, 2010, p.5). ${ }^{12}$

\footnotetext{
${ }^{10}$ Tradução livre: "Destreza digital significa ter as habilidades necessárias para viver, aprender e trabalhar em uma sociedade em que a comunicação e o acesso à informação são cada vez mais por meio de tecnologias digitais como plataformas da Internet, mídias sociais e dispositivos móveis".

${ }^{11}$ Tradução livre: "A capacidade de entender as informações apresentadas".

12 Tradução livre: "Ter destreza digital é ter acesso a uma ampla gama de práticas e recursos culturais que você pode aplicar a ferramentas digitais. É a capacidade de fazer, representar e compartilhar significado em diferentes modos e formatos; para criar, colaborar e comunicar de forma eficaz e para entender como e quando as tecnologias digitais podem ser mais bem utilizadas para apoiar esses processos".
} 
É importante mencionar que a falta desta habilidade pode ser verificada em cidadãos de todos os países do mundo, inclusive naqueles considerados desenvolvidos do ponto de vista tecnológico e educacional, como a Alemanha, Estados Unidos, Coréia do Sul, por exemplo. Contudo, a falta de digital literacy é especialmente verificável nas nações onde o processo educacional ofertado pelo Estado é precário ou está presente em menor grau de profundidade, como é o caso do Brasil.

E como a ausência de tal capacidade é a força propulsora da desinformação, é proposição do presenta artigo afirmar que somente a adoção de um processo educacional rigorosamente preocupado com a sustentabilidade e promoção da alteridade no ambiente digital é que servirá a combater eficazmente as Fake News.

\subsection{As notícias falsas veiculadas pela internet - fake news}

As notícias falsas (ou desinformação) em meios de divulgação de informação não são uma novidade. Segundo reportagem do jornal Folha de São Paulo, desde o século VI o Imperador Justiniano sofria com textos falsos que contribuíram para sua má reputação (FOLHA DE SÃO PAULO, 2017, p.1).

Por sua vez, Adrian Chen chama a atenção para o fato de que no ano de 1938, o diretor Orson Welles fez uma adaptação radiofônica realística da obra "Guerra dos Mundos", de H.G. Wells, às vésperas do dia das bruxas nos Estados Unidos da América. A narração trazia uma invasão alienígena em tempo real: a programação era intencionalmente interrompida para anunciar a chegada de extraterrestres e de meteoros ao país. Foi o que bastou para que o pânico fosse instalado em algumas cidades norte-americanas:

The next day, newspapers were full of stories like Dock's. "Thirty men and women rushed into the West 123rd Street police station," ready to evacuate, according to the Times. Two people suffered heart attacks from shock, the Washington Post reported. One caller from Pittsburgh claimed that he had barely prevented his wife from taking her own life by swallowing poison. The panic was the biggest story for weeks; a photograph of Bill Dock and his shotgun, taken the next day, by a Daily News reporter, went "the 1930s equivalent of viral" (CHEN, 2017, p.78). ${ }^{13}$

\footnotetext{
${ }^{13}$ Tradução livre: No dia seguinte, os jornais estavam cheios de histórias como a de Dock's. "Trinta homens e mulheres correram para a delegacia de polícia da West 123th Street", pronto para deixar a cidade, de acordo com o Times. Duas pessoas sofreram ataques cardíacos de choque, informou o Washington Post. Um interlocutor de Pittsburgh afirmou que ele quase não conseguiu impedir sua esposa de seifar sua própria vida, tomando veneno. O pânico foi a maior história por semanas; uma fotografia de Bill Dock e sua espingarda, levada no dia seguinte, por um repórter da Daily News, foi "o equivalente ao viral dos anos 30".
} 
Contemporaneamente, o que faz das notícias falsas uma preocupação a nível global (e, portanto, a justificar a temática do presente estudo) é que tal prática está hiperpotencializada, uma vez que está submetida à velocidade da informação na era digital. Desta maneira, portanto, a desinformação é experimentada em um grau nunca antes visto pela sociedade.

Esta afirmação ganha força principalmente porque é preciso levar em conta o atual cenário político mundial conflituoso, intricado e eivado de insegurança jurídica, que se traduz na "arena" perfeita para o surgimento e espraiamento da desinformação, principalmente porque se vive a era da "pós-verdade".

Pós-verdade foi a palavra eleita pelo Dicionário Oxford de Inglês, como sendo a palavra representativa do ano de 2016, diante da atitude do Presidente Donald Trump nas eleições norte-americanas. De acordo com o dicionário, a palavra é um adjetivo:

Relating to or denoting circumstances in which objective facts are less influential in shaping public opinion than appeals to emotion and personal belief. In this era of post-truth politics, it's easy to cherry-pick data and come to whatever conclusion you desire. Some commentators have observed that we are living in a post-truth age (OXFORD LIVING DICTIONARIES, 2017, p.1). ${ }^{14}$

Como visto, se de um lado as notícias falsas não são uma novidade, é preciso relembrar que, quando as Fake News estão submetidas ao imediatismo, instantaneidade, velocidade e potencial de propagação que contemporaneamente a Internet é capaz de proporcionar, elas ganham novos ares e contornos de periculosidade:

Donald Trump's victory has been a demonstration, for many people, of how the Internet can be used to achieve those very ends. Trump used Twitter less as a communication device than as a weapon of information warfare, rallying his supporters and attacking opponents with hundred-and-forty-character barrages. "I wouldn't be here without Twitter," he declared on Fox News in March. Yet the Internet didn't just give him a megaphone. It also helped him peddle his lies through a profusion of unreliable media sources that undermined the old providers of established fact. Throughout the campaign, fake-news stories, conspiracy theories, and other forms of propaganda were reported to be flooding social networks (CHEN, 2017, p.78-79). ${ }^{15}$

\footnotetext{
${ }^{14}$ Tradução livre: Relacionando ou denotando circunstâncias em que os fatos objetivos são menos influentes na formação da opinião pública do que apelos à emoção e à crença pessoal. Nesta era da política pós-verdade, é fácil pinçar dados e chegar a qualquer conclusão que você desejar. Alguns comentaristas observaram que estamos vivendo em uma era pós-verdade.

${ }^{15}$ Tradução livre: A vitória de Donald Trump foi uma demonstração, para muitas pessoas, de como a Internet pode ser usada para alcançar esses fins. Trump usou o Twitter menos como um dispositivo de comunicação do que como uma arma de guerra de informações, reunindo seus apoiadores e atacando oponentes com barreiras de cento e quarenta e quatro caracteres. "Eu não estaria aqui sem Twitter", declarou na Fox News em março. No entanto, a Internet não apenas lhe deu um megafone. Também o ajudou a vender suas mentiras por meio de uma
} 
Da aliança da prática antiga das Fake News com o atual contexto da "pós-verdade" e instantaneidade da informação, surge um cenário político e econômico repleto de discursos de ódio e polarizações nunca antes visto, principalmente porque a Internet, com seus fóruns, chats, redes sociais, aplicativos de mensagens, vídeos, blogs e podcasts é capaz de dar a voz, e sem qualquer tipo de filtro de quantidade e qualidade, a qualquer tipo de opinião:

Post-truth has also been abetted by the evolution of the media. The fragmentation of news sources has created an atomised world in which lies, rumour and gossip spread with alarming speed. Lies that are widely shared online within a network, whose members trust each other more than they trust any mainstream-media source, can quickly take on the appearance of truth. Presented with evidence that contradicts a belief that is dearly held, people have tendency to ditch the facts first. Well-intentioned journalistic practices bear blame too. The pursuit of "fairness" in reporting often creates phoney balance at the expense of truth. NASA scientist says Mars is probably uninhabited; Professor Snooks says it is teeming with aliens. It's really a matter of opinion (THE ECONOMIST, 2016, p.1). ${ }^{16}$

Logo, é importante conceituar o que são Fake News: "as the online publication of intentionally or knowingly false statements of fact" (KLEIN; WUELLER, 2017, p.6) ${ }^{17}$. Sendo que elas podem ser categorizadas em ao menos07 (sete) tipos, conforme Tabela 1.

Tabela 1. Categorias de Fake News

\begin{tabular}{|c|c|c|c|c|c|c|}
\hline $\begin{array}{c}\text { Sátira ou } \\
\text { paródia }\end{array}$ & $\begin{array}{l}\text { Conteúdo } \\
\text { enganador }\end{array}$ & $\begin{array}{l}\text { Conteúdo } \\
\text { impostor }\end{array}$ & $\begin{array}{l}\text { Conteúdo } \\
\text { fabricado }\end{array}$ & $\begin{array}{c}\text { Conexão } \\
\text { falsa } \\
\end{array}$ & $\begin{array}{c}\text { Contexto } \\
\text { falso } \\
\end{array}$ & $\begin{array}{c}\text { Contexto } \\
\text { manipulado }\end{array}$ \\
\hline $\begin{array}{c}\text { Sem } \\
\text { intenção de } \\
\text { causar um } \\
\text { mal, mas } \\
\text { com } \\
\text { potencial } \\
\text { para enganar }\end{array}$ & $\begin{array}{c}\text { Uso } \\
\text { enganoso da } \\
\text { informação } \\
\text { contra um } \\
\text { assunto ou } \\
\text { indivíduo }\end{array}$ & $\begin{array}{c}\text { Quando } \\
\text { fontes } \\
\text { genuínas são } \\
\text { usadas para } \\
\text { representar } \\
\text { notícias } \\
\text { falsas }\end{array}$ & $\begin{array}{c}\text { O novo } \\
\text { conteúdo é } \\
100 \% \text { falso, } \\
\text { feito para } \\
\text { desinformar } \\
\text { e causar } \\
\text { danos }\end{array}$ & $\begin{array}{c}\text { Quando } \\
\text { manchetes, } \\
\text { imagens e } \\
\text { legendas se } \\
\text { apresentam } \\
\text { de forma } \\
\text { diferente ao } \\
\text { conteúdo } \\
\text { posto }\end{array}$ & $\begin{array}{c}\text { Quando o } \\
\text { conteúdo } \\
\text { genuíno é } \\
\text { compartilhado } \\
\text { com um } \\
\text { contexto falso }\end{array}$ & $\begin{array}{c}\text { Quando a } \\
\text { informação } \\
\text { genuína ou } \\
\text { imagem é } \\
\text { manipulada } \\
\text { para enganar }\end{array}$ \\
\hline
\end{tabular}

Traduzido e adaptado de (WARDLE, 2017, p.1)

profusão de fontes de mídia não confiáveis que prejudicaram os antigos provedores dos fatos estabelecidos. Ao longo da campanha, estórias de fake-news, teorias de conspiração e outras formas de propaganda foram relatados inundando as redes sociais.

16 Tradução livre: A pós-verdade também foi incentivada pela evolução dos meios de comunicação. A fragmentação das fontes de notícias criou um mundo atomizado no qual as mentiras, rumores e fofocas se espalharam com uma velocidade alarmante. Mentiras que são amplamente compartilhadas on-line dentro de uma rede, cujos membros confiam uns nos outros mais do que confiam em qualquer fonte de mídia comum, podem rapidamente assumir a aparência da verdade. Apresentado com evidências que contradizem uma crença que é muito apreciada, as pessoas tendem a abandonar primeiro os fatos. As práticas jornalísticas bemintencionadas também são culpadas. A busca da equidade nos relatos geralmente cria falso equilíbrio à custa da verdade. Cientista da NASA diz que Marte é provavelmente desabitada; O professor Snooks diz que está cheio de alienígenas. É realmente uma questão de opinião.

${ }^{17}$ Tradução livre: Como as publicações on-line de intencionais ou conscientemente falsas declarações de fato. 
Estes tipos, por sua vez, podem servir a propósitos partidários e de: provocações, influência política, propaganda, jornalismo mal feito, paixão e obtenção de lucro (PORTAL POLITIZE, 2017, p.1). Claire Wardle (2017,p.5), inclusive, categoriza estes 07 (sete) tipos em três grandes classes: a) informações incorretas (mis-information), quando há compartilhamento de informações falsas, contudo sem danos a alguém; b) desinformação (dis-information), quando informações falsas são conscientemente compartilhadas para causar danos e; c) má informação (mal-information), quando informações genuínas e privadas são compartilhadas para a esfera pública com o intuito de causar danos.

Assim, como se verifica, o que caracteriza as Fake News (desinformação) são sua intencionalidade ou consciência (de quem as dissemina) e elas acabam tendo o condão de mobilizar facilmente a opinião pública e serem capazes não só de influenciar eleições presidenciais, mas também de causar celeumas internacionais, como as que envolvem a compra, por grupos políticos russos, de espaços publicitários no Google, Facebook e Twitter (PORTAL GIZMODO, 2017, p.1), visando disseminar informações falsas de maneira maciça para interferir no processo eleitoral norte-americano, criando, por exemplo, notícias difamatórias e caluniosas a respeito da então candidata Hillary Clinton (GAZETA DO POVO, 2017, p.1).

Neste caso em específico, o Governo russo está sendo acusado de decisiva influência no resultado que culminou na eleição do Presidente norte-americano Donald Trump (PORTAL GIZMODO, 2017, p.1). Este acontecimento serviu de paradigma a países de todo o mundo, os quais - especialmente aqueles que passaram no ano de 2017, por processos eleitorais - demonstram preocupação com o tema.

É o caso da França, onde diversos comitês de monitoramento e plataformas de checagens de notícias foram criados (O ESTADO DE SÃO PAULO, 2017, p.1). Já na Alemanha, as medidas estão sendo mais drásticas, por meio de proposta de lei que impõe multas de até 50 milhões de euros às redes sociais que não tomarem medidas preventivas contra a desinformação (JORNAL PÚBLICO, 2017, p.1).

Não é à toa que o Relator Especial das Nações Unidas sobre Liberdade de Opinião e Expressão, o Representante da Organização para a Segurança e Cooperação na Europa (OSCE) sobre Liberdade de Comunicação, o Relator Especial da Organização dos Estados Americanos (OEA) sobre Liberdade de Expressão e o Relator Especial da Comissão Africana dos Direitos Humanos e dos Povos (CADHP) sobre Liberdade de Expressão e Acesso à 
Informação externaram suas opiniões de que as notícias falsas representam uma ameaça global aos Direitos Humanos:

\begin{abstract}
Expressing concern that disinformation and propaganda are often designed and implemented so as to mislead a population, as well as to interfere with the public's right to know and the right of individuals to seek and receive, as well as to impart, information and ideas of all kinds, regardless of frontiers, protected under international legal guarantees of the rights to freedom of expression and to hold opinions (UN NEWS CENTRE, 2017, p.1). ${ }^{18}$
\end{abstract}

No Brasil, com a chegada das eleições de 2018, a tônica não foi diferente, visto que o Ministro do STF, Alexandre de Moraes, publicamente externou sua inquietação com as Fake News e seu poder de influência (PORTAL O DIA, 2017, p.1). De outro lado, o Ministro da Justiça, representantes do TSE e do Exército se reuniram para traçar planos visando o combate às notícias falsas (O ESTADO DE SÃO PAULO, 2017, p.1). Visando combater as Fake News durante as campanhas eleitorais municipais de 2020, o TSE lançou, em janeiro, a página web "Fato ou Boato?"19 contendo informações para reconhecer conteúdos enganosos e apontando agências de checagem de conteúdo que são parceiras do Programa de Enfrentamento a Desinformação nas Eleições 2020.

Em um ambiente digital dominado por enormes quantidades de correntes de e-mails e mensagens via WhatsApp e Facebook que viralizam em escala geométrica na medida em que vão sendo compartilhados de maneira indiscriminada e sem filtros, tais políticas de combate à desinformação ganham crucial importância.

Neste sentido, o jornal O Estado de São Paulo dá conta de que 12 milhões de pessoas difundem reiteradamente, notícias falsas sobre política no Brasil (O ESTADO DE SÃO PAULO, 2017, p.1). E o poder de mobilização e do potencial de produção de nefastos efeitos da desinformação podem ser aferidos em alguns exemplos recentes dados pela mídia:

\begin{abstract}
O juiz Sergio Moro é filiado ao PSDB. Gilberto Gil chamou Moro de 'juizinho fajuto'. Hillary Clinton participa de seitas satanistas. Presidente do Banco Mundial critica Governo Temer. O que há em comum entre essas quatro notícias? Todas são mentirosas, partilhadas milhares de vezes, mas foram divulgadas como verdadeiras dentro do fenômeno das chamadas 'Fake News', ou 'pós verdade'. Não é acaso que o Papa Francisco, ele mesmo vítima de Fake News (uma notícia se espalhou durante as eleições americanas dizendo que ele apoiava Trump), tenha entrado no debate dizendo que "a desinformação é provavelmente o maior pecado que um meio de comunicação pode cometer, porque dirige a opinião pública a uma direção única e omite parte da verdade (EL PAÍS, 2017, p.1).
\end{abstract}

\footnotetext{
18 Tradução livre: Expressando a preocupação de que a desinformação e a propaganda sejam muitas vezes projetadas e implementadas de modo a induzir em erro uma população, além de interferir com o direito público ao conhecimento e o direito dos indivíduos de buscar e receber, além de transmitir informações e ideias de todos os tipos, independentemente das fronteiras, protegidos sob garantias jurídicas internacionais dos direitos à liberdade de expressão e de opiniões.

${ }^{19}$ Disponível em: http://www.justicaeleitoral.jus.br/fato-ou-boato/
} 
A respeito das práticas relacionadas às Fake News, nem mesmo todos os anos de consumo irrestrito de carne bovina, o reconhecimento de mercados internacionais acerca da excelência da qualidade da carne brasileira e a existência de todas as normas e aparatos estatais de controles de vigilância sanitária, foram suficientes para evitar o aturdimento generalizado da população com a divulgação indiscriminada e manipulada de notícias da Operação Carne Fraca da Polícia Federal, na qual frigoríficos como a JBS e outros precisaram gastar enormes quantidades de tempo e dinheiro para lançar campanhas publicitárias incentivando a não paralização do consumo e, também, para rebater a imediata crença estabelecida de que toda carne vendida em supermercados continha papelão ou ácido cancerígeno (UOL, 2017, p.1).

Pode-se compreender, portanto, que as Fake News são, dentre todas as más condutas sociais da era digital, as que mais estão relacionadas à ausência de educação para o bom e correto uso das tecnologias, porque dependem exclusivamente do comportamento do usuário de Internet para existir e se propagar.

De outro lado, e paradigmaticamente, são as que podem ser mais facilmente solucionadas, desde que as políticas de combate à desinformação, por evidente, estejam focadas para o centro do problema, e não para a adoção de soluções paliativas.

Afirma-se isto porque as recentes e parcas ações afirmativas que se debruçam sobre o tema estão todas calcadas em errôneas estratégias, pois é proposição do presente texto asseverar que não é impondo multa ao Facebook ou Google, ou ainda, criando-se plataformas de checagem ou validação de informações que se combaterá eficazmente o problema.

Até o presente momento, nenhuma política pública voltada ao combate das notícias falsas de Internet foi pensada e implementada tendo por foco o que realmente interessa, ou seja, a falta de educação para o uso das tecnologias. Denota-se que os agentes públicos ainda não se deram conta de que o cerne das Fake News é o desconhecimento do usuário acerca do seu papel e responsabilidade social, além de como bem usar o aparato tecnológico posto à disposição.

Muito menos atentaram para o fato de que é aproveitando-se da ausência de educação tecnológica que, dolosamente, pessoas manipulam e falseiam informações visando mobilizar a opinião pública em torno de interesses (escusos ou não) de ordem política e econômica. 
Inclusive é de se asseverar que as atuais formas adotadas por diversos países, inclusive o Brasil, para combate às notícias falsas, ainda traz em si o potencial perigo de infração às garantias fundamentais:

No Projeto de Lei da Câmara n $^{\circ}$ 110, de 2017, que modifica a Lei 9.504/1997 (Lei
Eleitoral) no artigo 57-B, havia sido incluído um parágrafo (§ 6 $6^{\circ}$.) que atribuía aos
provedores de serviços na Internet a obrigação de suspensão de conteúdo ofensivo
falso ou que incitasse o ódio contra candidato, partido ou coligação. De logo, vozes
se levantaram e passaram a bradar que a medida legislativa instituía a censura na
Internet. Mesmo setores da imprensa tradicional ecoaram esse discurso. A ANJ
(Associação Nacional de Jornais), a ABERT (Associação Brasileira de Emissoras
de Rádio e Televisão), a ANER (Associação Nacional de Editores de Revistas) e a
ABI (Associação Brasileira de Imprensa) se pronunciaram contra a medida. O
Comitê Gestor da Internet (CGI.br) também publicou nota, pedindo o veto do
dispositivo, o que terminou ocorrendo (REINALDO FILHO, 2017, p.1).

No país, e como anteriormente visto, se de um lado há políticas públicas eficientes que possibilitaram o fácil e amplo acesso a dispositivos tecnológicos pela população, o mesmo não se pode falar quando o assunto são as práticas que visam combater as notícias falsas de Internet. Pela atual tônica das políticas públicas brasileiras no trato da questão, entende-se que as Fake News não irão diminuir ou acabar; pelo contrário, podem aumentar e se perpetuar cada vez mais, principalmente porque não é levado em consideração o fato de que a Internet é um ambiente propício ao anonimato e que dificulta o rastreamento de informações, (até mesmo diante da falta de aparato policial suficiente para isto) que facilmente escapam ao controle social e estatal.

Ao mesmo tempo, grandes empresas como Google, Facebook, Apple e Microsoft não têm por política a inserção, em seus Termos de Uso, de aspectos relacionados à ética, moralidade, socioambientalismo, diversidade e sustentabilidade. Desta forma, por evidente, o papel educacional a respeito da responsabilidade, da função social e do correto uso das tecnologias tem que ser assumido de forma premente pelo Governo Federal.

\section{Da necessidade de elaboração e implementação de políticas públicas de educação para o uso das tecnologias}

Externando preocupação acerca de uma educação de base voltada integralmente à era digital, Bruno Pires Malaquias assevera que "para navegar satisfatoriamente na rede mundial de computadores e, assim, desfrutar de todo o conteúdo da web, é preciso um bom 
nível de conhecimentos provenientes de uma escolarização feita com qualidade, a qual inclua, em especial, a informática” (MALAQUIAS, 2003, p.1).

Isso porque se verifica que é o internauta que se encontra sozinho, sem amparo e com a exclusiva responsabilidade de filtrar o conteúdo informacional. Isto é bastante preocupante, principalmente porque a vulnerabilidade do usuário, nestes casos, como já mencionado, é hiperpotencializada.

Corroborando esta afirmação, é preciso relembrar que ainda é reduzido o número de pessoas que utiliza em seus dispositivos tecnológicos, software antivírus ou, ainda, poucos são os jovens consumidores submetidos a algum tipo de filtro de qualidade e quantidade. Estudo do Unicef demonstra que $46 \%$ dos adolescentes entrevistados não tem qualquer tipo de controle parental (UNICEF, 2013, p.76), 39\% dos que possuem contas em redes sociais já se encontrou pessoalmente com alguém que conheceu online (UNICEF, 2013, p.48). E que $54 \%$ deles adicionam em seus perfis, pessoas desconhecidas, sendo $21 \%$ de forma incondicional e 33\% condicionalmente (UNICEF, 2013, p.45).

Diante deste cenário de incertezas e iminentes riscos, serve o presente estudo para alertar acerca da necessidade de o Governo Federal brasileiro preencher o mencionado vazio da incompreensão por meio de ações afirmativas consubstanciadas em políticas públicas de educação para o bom e correto uso das tecnologias, até como forma de se atender o disposto na Constituição da República e na legislação infraconstitucional já existente no país.

Isso porque quando o assunto são direitos sociais, o Estado brasileiro necessita agir de maneira proativa fazendo uso de ações concretas e efetivas que garantam e promovam os direitos fundamentais ao desenvolvimento da nação (SECRETARIA NACIONAL DE PROMOÇÃO DA IGUALDADE RACIAL DO MINISTÉRIO DOS DIREITOS HUMANOS, 2017, p.1):

\footnotetext{
É preciso, assim, destacar que as políticas públicas têm ínsita ligação com o Direito, especialmente com o Direito Constitucional, na medida em que se referem a um conjunto de metas e programas normativos, geralmente veiculados por meio de lei ou medida provisória, que tem o objetivo de realizar os direitos sociais e fundamentais garantidos na Constituição da República Federativa do Brasil de 1988 (BRADBURY, 2016, p.21-22).
}

Sem a pretensão de abordar ou apontar no presente estudo quais seriam as melhores práticas ou soluções que as políticas públicas sobre o tema em debate deveriam adotar e implementar, cabe afirmar que elas são o instrumento adequado à garantia dos direitos constitucionais (BRADBURY, 2016, p.22). 
A Constituição da República, em seu art. $6^{\circ}$, garante o direito social à educação, sendo que o artigo 24, inciso IX pode ser interpretado em conjunto com o art. $7^{\circ}$ da Lei 13.005/2014 - Plano Nacional de Educação - PNE - para estabelecer uma responsabilidade solidária entre a União, Estados e Municípios, tudo isso como forma de dar suporte ao que preconiza o artigo 205 da Constituição: “A educação, direito de todos e dever do Estado e da família, será promovida e incentivada com a colaboração da sociedade, visando ao pleno desenvolvimento da pessoa, seu preparo para o exercício da cidadania e sua qualificação para o trabalho" (CONSTITUIÇÃO FEDERAL, 1988, p.1).

Não obstante a Lei de Diretrizes e Bases da Educação (LDB), Lei 9.394/1996, trazer diversos artigos que determinam as finalidades sociais do ensino básico, médio e superior em torno da promoção da cidadania e dignidade da pessoa humana ${ }^{20}$, ela foi alterada por intermédio da Lei 12.145/2017, para incluir em seu bojo 04 (quatro) grandes áreas de educação, todas vinculadas à questão da tecnologia:

Art. 35-A. A Base Nacional Comum Curricular definirá direitos e objetivos de aprendizagem do ensino médio, conforme diretrizes do Conselho Nacional de Educação, nas seguintes áreas do conhecimento: I - linguagens e suas tecnologias; II - matemática e suas tecnologias; III - ciências da natureza e suas tecnologias; IV ciências humanas e sociais aplicadas.

Art. 36. O currículo do ensino médio será composto pela Base Nacional Comum Curricular e por itinerários formativos, que deverão ser organizados por meio da oferta de diferentes arranjos curriculares, conforme a relevância para o contexto local e a possibilidade dos sistemas de ensino, a saber: I - linguagens e suas tecnologias; II - matemática e suas tecnologias; III - ciências da natureza e suas

\footnotetext{
${ }^{20}$ Neste sentido, vide o art. 22: A educação básica tem por finalidades desenvolver o educando, assegurar-lhe a formação comum indispensável para o exercício da cidadania e fornecer-lhe meios para progredir no trabalho e em estudos posteriores. Os incisos II, III e IV do art. 35. O ensino médio, etapa final da educação básica, com duração mínima de três anos, terá como finalidades: II - a preparação básica para o trabalho e a cidadania do educando, para continuar aprendendo, de modo a ser capaz de se adaptar com flexibilidade a novas condições de ocupação ou aperfeiçoamento posteriores; III - o aprimoramento do educando como pessoa humana, incluindo a formação ética e o desenvolvimento da autonomia intelectual e do pensamento crítico; IV - a compreensão dos fundamentos científico-tecnológicos dos processos produtivos, relacionando a teoria com a prática, no ensino de cada disciplina. Ainda, o art. 43: A educação superior tem por finalidade: I - estimular a criação cultural e o desenvolvimento do espírito científico e do pensamento reflexivo; II - formar diplomados nas diferentes áreas de conhecimento, aptos para a inserção em setores profissionais e para a participação no desenvolvimento da sociedade brasileira, e colaborar na sua formação contínua; III - incentivar o trabalho de pesquisa e investigação científica, visando o desenvolvimento da ciência e da tecnologia e da criação e difusão da cultura, e, desse modo, desenvolver o entendimento do homem e do meio em que vive; IV - promover a divulgação de conhecimentos culturais, científicos e técnicos que constituem patrimônio da humanidade e comunicar o saber através do ensino, de publicações ou de outras formas de comunicação; V - suscitar o desejo permanente de aperfeiçoamento cultural e profissional e possibilitar a correspondente concretização, integrando os conhecimentos que vão sendo adquiridos numa estrutura intelectual sistematizadora do conhecimento de cada geração; VI - estimular o conhecimento dos problemas do mundo presente, em particular os nacionais e regionais, prestar serviços especializados à comunidade e estabelecer com esta uma relação de reciprocidade; VII - promover a extensão, aberta à participação da população, visando à difusão das conquistas e benefícios resultantes da criação cultural e da pesquisa científica e tecnológica geradas na instituição.
} 
tecnologias; IV - ciências humanas e sociais aplicadas; V - formação técnica e profissional (LDB, 1996).

Também o Plano Nacional de Educação (PNE) traz, dentre as suas diretrizes, as seguintes:

Art. $2^{\circ}$. São diretrizes do PNE: III - superação das desigualdades educacionais, com ênfase na promoção da cidadania e na erradicação de todas as formas de discriminação; IV - melhoria da qualidade da educação; V - formação para o trabalho e para a cidadania, com ênfase nos valores morais e éticos em que se fundamenta a sociedade; VI - promoção do princípio da gestão democrática da educação pública; VII - promoção humanística, científica, cultural e tecnológica do País; X - promoção dos princípios do respeito aos direitos humanos, à diversidade $\mathrm{e}$ à sustentabilidade socioambiental (PNE, 2014).

Por sua vez, o Marco Civil da Internet, Lei 12.965/2014, estabeleceu princípios, garantias, direitos e deveres para o uso da Internet no Brasil, obrigando o Estado à prestação da educação para o uso seguro, consciente e responsável da Internet:

Art. 26. O cumprimento do dever constitucional do Estado na prestação da educação, em todos os níveis de ensino, inclui a capacitação, integrada a outras práticas educacionais, para o uso seguro, consciente e responsável da internet como ferramenta para o exercício da cidadania, a promoção da cultura e o desenvolvimento tecnológico (MARCO CIVIL DA INTERNET, 2014).

Além disto, determina que:

Art. 27. As iniciativas públicas de fomento à cultura digital e de promoção da internet como ferramenta social devem: I - promover a inclusão digital; II - buscar reduzir as desigualdades, sobretudo entre as diferentes regiões do País, no acesso às tecnologias da informação e comunicação e no seu uso; e III - fomentar a produção e circulação de conteúdo nacional (MARCO CIVIL DA INTERNET, 2014).

A atual ausência de políticas públicas que tenham por escopo a educação para o uso das tecnologias, afronta todo este arcabouço normativo. Denota-se que tanto a Constituição da República, quanto a LDB, o PNE e o Marco Civil da Internet trazem a obrigação de uma promoção da inclusão digital pelo Estado, que deve primar pela autodeterminação e emancipação da sociedade, que se dá pela redução das desigualdades por meio de um ensino que garanta a capacitação plena para a era digital, de onde, e agora por força de lei, todas as áreas básicas do conhecimento estão obrigatoriamente vinculadas à tecnologia.

\section{Conclusão}


Sabido é que o desenvolvimento humano é indissociável da tecnologia, pois o Homem necessita dela para exercer plenamente sua cidadania. A relação de interdependência, portanto, é mútua:

Tanto a Internet quanto as redes sociais, somente são passíveis de existência devido ao desenvolvimento tecnológico alcançado pela sociedade contemporânea. É a tecnologia que estabelece a conexão direta entre a política e as redes sociais, fazendo do cidadão o novo sujeito político-tecno-social (PAMPLONA; FREITAS, 2015, p.100).

Neste sentido, Ralph Waldo Emerson assevera: "The human body is the magazine of inventions, the patent-office, where are the models from which every hint was taken. All the tools and engines on earth are only extensions of its limbs and senses." ${ }^{21}$ (EMERSON, 2008, p.79).

Portanto, mais do que renúncias fiscais que proporcionem à sociedade brasileira o acesso a dispositivos tecnológicos, o Governo Federal deve ater-se à necessidade de incluir nos programas básicos de educação, a questão do papel social e da responsabilidade do usuário, incentivando e instruindo acerca do bom e correto uso das tecnologias:

\begin{abstract}
E o modo de se alcançar este processo de raciocínio lógico e consciente, é o da educação. A solução para os malefícios apontados neste artigo passa, necessariamente, pela conscientização e educação para o uso da tecnologia, o que pode ser traduzido da seguinte maneira: Internet Segura $=$ (Usuário + Conscientização + Educação para o uso da tecnologia) (PARCHEN; FREITAS, 2016, p.20).
\end{abstract}

Como visto, a isenção ou suspensão de impostos sobre aparatos eletrônicos é uma política pública equivocada, pois nada adianta dar "ares de inclusão digital” ao país somente porque há estatísticas relacionadas à grande quantidade de pessoas que possuem ou têm acesso a um computador, tablet, smartphone, entre outros.

Permitir o fácil e barato acesso a dispositivos tecnológicos ao mesmo tempo em que há o completo descuido com a necessária e suficiente instrução (digital literacy), principalmente da parcela mais jovem da população e, portanto, mais vulnerável, é criar uma gama significante de "analfabetos digitais", ou seja, os marginalizados do século XXI. Com isto, os riscos a que a sociedade brasileira da era digital está submetida com relação à desinformação serão cada vez maiores.

\footnotetext{
${ }^{21}$ Tradução livre: O corpo humano é a revista de invenções, o escritório de patentes, onde estão os modelos a partir do qual cada sugestão foi tomada. Todas as ferramentas e motores na Terra são apenas extensões de seus membros e sentidos.
} 
Neste contexto de incompreensão e falta de habilidades e destreza para a era digital, a prática das Fake News encontra terreno fértil para se propagar. Ocorre que é preciso lembrar que se o risco - dentro do que já foi mencionado no presente estudo por Ulrich Beck - está intimamente ligado ao processo de tomada de decisão, quanto maior a conscientização, maior será a cautela; logo, quanto maior for a incidência e a qualidade da educação para o uso das tecnologias, maior será a previsão e o controle das ações humanas, que aumentariam a ponto de diminuir ou afastar a ocorrência das Fake News. Neste sentido:

\begin{abstract}
Quizás en este punto sea donde más se necesita la alfabetización digital, no necesariamente para distinguir lo verdadero de lo falso, o para diferenciar entre las subcategorías de Fake News o sus intenciones, sino para leer todos los medios digitales con el tipo de resiliencia escéptica que genera la alfabetización crítica (MCDOUGALL; BRITES; COUTO; LUCAS, 2019, p. 209). ${ }^{22}$
\end{abstract}

Portanto, é urgente a formulação de políticas públicas que possam ir além da simples concessão de benefícios fiscais que permitam o fácil e barato acesso aos dispositivos tecnológicos: a preocupação com a digital literacy e com a educação para o uso das tecnologias é questão premente de garantia de direitos fundamentais e dignidade da pessoa humana como eficaz forma para se mitigar o analfabetismo digital e assim, como consequência, diminuir também os maus comportamentos ligados às Fake News:

Desta forma, espera-se da educação e da escola que, além do cumprimento das funções sociais e pedagógicas que lhes são próprias, sejam indutoras de novas formas de sociabilidade humana, que influenciem o padrão de desenvolvimento e a consolidação da democracia (AGUIAR, 2006, p.138).

Somente o correto processo instrucional conseguirá ressignificar o usuário da tecnologia, tirando-o da atual inércia que lhe inflige prejuízos de ordem social e econômica, privilegiando a construção de uma autoproteção contra as más práticas na Internet, especialmente as notícias falsas. As políticas públicas educacionais são, portanto, o instrumento de empoderamento e emancipação da sociedade digital brasileira para que ela possa ter a consciência plena do seu papel de protagonista na construção de um ambiente benéfico a todos:

Outro tema que surge na educação ao se pensar sobre a coesão social em âmbito
global é a ideia de que podem existir formas de 'cidadania global'. Pelo menos no
Japão e Inglaterra, surgiram, ultimamente, certas demandas que adotam a ideia de
um novo tipo de 'cidadão' que reconhece a interdependência existente no mundo,
por meio da qual as ações das pessoas podem afetar a vida de muitas outras em
lugares muito distantes. Este tipo de cidadão age de forma independente de seu

${ }^{22}$ Tradução livre: “Talvez seja aqui que a alfabetização digital seja mais necessária, não necessariamente para distinguir o verdadeiro do falso, ou diferenciar entre as subcategorias de notícias falsas ou suas intenções, mas para ler toda a mídia digital com o tipo de resiliência cética que a alfabetização crítica gera". 
Estado-nação, em uma tentativa de desenvolver uma moral universal que visa a construção de uma sociedade global mais justa (BEECH; GVIRTZ, 2009, p.353$354)$.

É necessário, portanto, promover a verdadeira inclusão digital, que somente se dará dotando os cidadãos brasileiros de digital literacy, pois somente ela levará o Brasil ao salutar progresso e desenvolvimento sustentável que também se almeja e se preconiza no campo tecnológico e digital.

\section{Referências}

AGUIAR, Márcia Ângela da S. Desenvolvimento com igualdade social, educação e gestão escolar: notas para um debate. In. Políticas públicas e gestão da educação: polêmicas, fundamentos e análises. FERREIRA, Naura Syria Carspeto (org). Brasília: Líber Livro Editora. 2006.

ASSOCIAÇÃO BRASILEIRA DA INDÚSTRIA ELÉTRICA E ELETRÔNICA. ABINEE. Releases 2015. Disponível em: http://www.abinee.org.br/noticias/rel2015.htm. Acesso em 04 jun. 2020.

BEECH, Jason; GVIRTZ, Silvina. Micropolítica escolar e coesão social na América Latina. In. Políticas educacionais e coesão social: uma agenda latino-americana. SCHWARTMAN, Simon; COX, Cristián (editores). Rio de Janeiro: Elsevier; São Paulo: IFHC, 2009.

BECK, Ulrich. La sociedade del riesgo global. Madrid: Siglo XXI Editores S.A, 1999

BRADBURY, Leonardo Cacau Santos La. Direito a educação: judicialização, políticas públicas e efetividade do direito fundamental. $2^{\mathrm{a}}$ ed. Curitiba: Juruá, 2016.

BRASIL. Constituição da República Federativa do Brasil. Disponível em: http://www.planalto.gov.br/ccivil_03/constituicao/constituicao.htm. Acesso em 04 jun. 2020. BRASIL. Lei $\mathbf{n}^{\circ}$ 9.394, de 20 de dezembro de 1996. Estabelece as diretrizes e bases da educação nacional. Disponível em: http://www.planalto.gov.br/ccivil_03/leis/L9394.htm. Acesso em 04 jun. 2020.

BRASIL. Lei $\mathbf{n}^{0}$ 12.965, de 23 de abril de 2014. Estabelece princípios, garantias, direitos e deveres para o uso da Internet no Brasil. Disponível em: 
http://www.planalto.gov.br/ccivil_03/_ato2011-2014/2014/lei/112965.htm. Acesso em 04 jun. 2020.

BRASIL. Lei no 13.005, de 25 de junho de 2014. Aprova o Plano Nacional de Educação PNE dá outras providências. Disponível em: http://www.planalto.gov.br/CCIVIL_03/_Ato2011-2014/2014/Lei/L13005.htm. Acesso em 04 jun. 2020.

CENTRO REGIONAL DE ESTUDOS PARA O DESENVOLVIMENTO DA SOCIEDADE DA INFORMAÇÃO (CETIC.BR). Pesquisa TIC domicílios 2019. Disponível em: https://www.cetic.br/pt/arquivos/domicilios/2019/domicilios/. Acesso em 04 jun. 2020.

CHEN, Adrian. The Fake News fallacy. The New Yorker. 9/4/2017, Vol. 93 Issue 26, p7883.

EMERSON, Ralph Waldo. The collected Works of Ralph Waldo Emerson. WILSON, Douglas Emory (organizador). Harvard University Press: 2008, p. 79. Disponível em: https://books.google.com.br/books?id=y4_SXyx8zwkC\&printsec=frontcover\&hl=pt-

BR\&source=gbs_ge_summary_r\&cad=0\#v=onepage\&q\&f=false. Acesso em 04 jun. 2020. FUNDO DAS NAÇÕES UNIDAS PARA A INFÂNCIA - UNICEF. O uso da Internet por adolescentes. $\quad 2013.2$ Disponível em: https://www.unicef.org/brazil/pt/br_uso_internet_adolescentes.pdf. Acesso em 04 jun. 2020. INSTITUTO BRASILEIRO DE GEOGRAFIA E ESTATÍSTICA. IBGE. PNAD 2018 Contínua. Disponível em: https://www.ibge.gov.br/estatisticas/sociais/trabalho/17270-pnadcontinua.html?edicao=27138\&t=resultados. Acesso em 04 jun. 2020.

JORNAL EL PAÍS. O mundo governado por mentiras das 'Fake News' abre ciclo de debates FAAP-EL PAÍS. Disponível em: https://brasil.elpais.com/brasil/2017/04/30/politica/1493559929_642710.html. Acesso em 04 jun. 2020.

JORNAL FOLHA DE SÃO PAULO. Notícias falsas existem desde o século 6, afirma historiador Robert Darnton. Disponível em: http://www1.folha.uol.com.br/ilustrissima/2017/02/1859726-noticias-falsas-existem-desde-oseculo-6-afirma-historiador-robert-darnton.shtml. Acesso em 04 jun. 2020. 
JORNAL GAZETA DO POVO. Russos usaram o Facebook para criar divisões no Black Lives Matter e entre muçulmanos. Disponível em: http://www.gazetadopovo.com.br/ideias/russos-usaram-o-facebook-para-criar-divisoes-noblack-lives-matter-e-entre-muculmanos-8i988rmb1d0zdenj251o4ed7w. Acesso em 04 jun. 2020.

JORNAL O ESTADO DE SÃO PAULO. França cria grupo contra 'Fake News'. Disponível em:http://internacional.estadao.com.br/noticias/geral,franca-cria-grupo-contrafake-news, 70001683496. Acesso em 04 jun. 2020.

JORNAL O ESTADO DE SÃO PAULO. Na web, 12 milhões difundem Fake News políticas. Disponível em:http://politica.estadao.com.br/noticias/geral,na-web-12-milhoesdifundem-fake-news-politicas,70002004235. Acesso em 04 jun. 2020.

JORNAL O ESTADO DE SÃO PAULO: TSE, Justiça e Defesa montam grupo para combater Fake News no período eleitoral. Disponível em: http://cultura.estadao.com.br/blogs/direto-da-fonte/gilmar-mendes-e-torquato-jardim-entreoutros-fazem-plano-para-combater-fake-news-no-periodo-eleitoral/. Acesso em 04 jun. 2020. JORNAL O GLOBO. Brasil é considerado o $^{\circ}$ país mais vulnerável a vírus que sequestra informações de computadores. Disponível em:https://oglobo.globo.com/economia/brasil-considerado-6-pais-mais-vulneravel-virus-quesequestra-informacoes-de-computadores-21370922. Acesso em 04 jun. 2020.

JORNAL O GLOBO. Governo anuncia prorrogação de incentivo fiscal para inclusão digital. Disponível em: https://oglobo.globo.com/economia/governo-anuncia-prorrogacaode-incentivo-fiscal-para-inclusao-digital-13683177. Acesso em 04 jun. 2020.

JORNAL PÚBLICO: Alemanha propõe multas de até 50 milhões de euros no combate às notícias falsas.

Disponível em: https://www.publico.pt/2017/03/14/tecnologia/noticia/alemanha-aperta-o-cerco-as-redessociais-por-causa-das-noticias-falsas-1765165. Acesso em 04 jun. 2020.

KLEIN, David O; WUELLER, Joshua R. Fake News: a legal perspective. Journal of Internet Law. Volume 20, number 10, april 20107. Disponível em: http://web.b.ebscohost.com/ehost/pdfviewer/pdfviewer?vid=2\&sid=164099d4-40c3-44b5b62e-c94835037ede\%40sessionmgr101. Acesso em 04 jun. 2020. 
LANKSHEAR, Colin; KNOBEL, Michele. Digital literacy and digital literacies: policy, pedagogy and research considerations for education. Revista Digital Kompetanse, 1-2006, vol.1, side 12-24. Disponível em: http://everydayliteracies.net/files/digital_kompetence_2006.pdf. Acesso em 05 jun. 2020.

MALAQUIAS, Bruno Pires. O Analfabetismo Digital. Instituto Brasileiro de Direito da Informática - IBDI, 2003. Disponível em:https://www.slideshare.net/nathaliacamargo33/ibdiinstituto-brasileiro-de-poltica-e-direito-da-informtica. Acesso em 04 jun. 2020.

MCDOUGALL, Julian; BRITES, Maria-José; COUTO, Maria-João; LUCAS, Catarina. Alfabetización digital, Fake News y educación. Cultura y Educación, 31:2, 2019, P. 203212.

O'BRIEN, Dick. ISTR Ransomware 2017. Special Report Disponível em: https://www.symantec.com/content/dam/symantec/docs/security-center/white-papers/istrransomware-2017-en.pdf. Acesso em 04 jun. 2020.

ONU. UN News Centre. Amid rise of 'Fake News,' authorities should ensure truthful info reaches public - $\mathbf{U N}$, regional experts. Disponível em: http://www.un.org/apps/news/story.asp?NewsID=56336\#.WfyeJ9iWxhE. Acesso em 04 jun. 2020.

OXFORD LIVING DICTIONARIES. Definition of post-truth. Disponível em: https://en.oxforddictionaries.com/definition/post-truth. Acesso em 04 jun. 2020.

PAMPLONA, Danielle Anne; FREITAS, Cinthia Obladen de Almendra. Exercício Democrático: a tecnologia e o surgimento de um novo sujeito. Pensar (UNIFOR), Fortaleza. v. 20, p. 82-105, jan/abr. 2015.

PARCHEN, Charles Emmanuel; FREITAS, Cinthia Obladen de Almendra. Educação para uso das TICs: uma questão de direitos humanos. Revista de Direito Empresarial. Belo Horizonte: Editora Fórum. vol. 13. nº1. Jan/abr 2016.

PAYTON, Sarah; HAGUE, Cassie. Digital literacy in practice: case studies of primary and secondary classrooms. Futurelab, United Kingdom, 2010. Disponível em: http://www.futurelab.org.uk. Acesso em 05 jun. 2020. 
PORTAL GIZMODO. Google, Facebook e Twitter testemunham sobre interferência russa na eleição dos EUA. Disponível em: http://gizmodo.uol.com.br/google-facebooktwitter-testemunham-interferencia-russa/. Acesso em 04 jun. 2020.

PORTAL GIZMODO. Tudo o que sabemos sobre a interferência russa nos anúncios do Facebook, Twitter e Google. Disponível em: http://gizmodo.uol.com.br/interferencia-russaanuncios-congresso/. Acesso em 04 jun. 2020.

PORTAL O DIA. Ministro do Supremo alerta sobre 'Fake News' nas eleições. Disponível em: http://odia.ig.com.br/brasil/2017-10-31/ministro-do-supremo-alerta-sobre-fake-newsnas-eleicoes.html. Acesso em 04 jun. 2020.

PORTAL POLITIZE. Notícias falsas e pós-verdade: o mundo das Fake News e da (des)informação. Disponível em: http://www.politize.com.br/noticias-falsas-pós-verdade/. Acesso em 04 jun. 2020.

PORTAL UOL. HUE BR: Brasileiros ganham fama por mau comportamento em jogos online. Disponível em: http://jogos.uol.com.br/ultimas-noticias/2014/09/03/hue-brbrasileiros-ganham-ma-fama-por-mau-comportamento-em-jogos-

online.htm?cmpid=copiaecolahttp://jogos.uol.com.br/ultimas-noticias/2014/09/03. Acesso em 04 jun. 2020.

PORTAL UOL. Papelão, ácido cancerígeno, exagero da PF: você entendeu a Carne Fraca? Disponível em: http://economia.uol.com.br/noticias/redacao/2017/03/25/papelaoacido-cancerigeno-exagero-da-pf-voce-entendeu-a-carne-fraca.htm. Acesso em 04 jun. 2020.

REINALDO FILHO, Demócrito. O trecho vetado da "reforma eleitoral" que obrigava a suspensão de conteúdo inserido por usuário anônimo em redes sociais. Portal Jus Navegandi. Disponível em: https://jus.com.br/artigos/61506/o-trecho-vetado-da-reformaeleitoral-que-obrigava-a-suspensao-de-conteudo-inserido-por-usuario-anonimo-em-redessociais. Acesso em 04 jun. 2020.

SECRETARIA NACIONAL DE PROMOÇÃO DA IGUALDADE RACIAL DO MINISTÉRIO DOS DIREITOS HUMANOS. O que são ações afirmativas. Disponível em: http://www.seppir.gov.br/assuntos/o-que-sao-acoes-afirmativas; Acesso em 04 jun. 2020. 
SYMANTEC. Norton Cyber Security Insights Report 2016. Disponível em: http://now.symassets.com/content/dam/norton/global/pdfs/norton_cybersecurity_insights/201 6-Norton-Cyber-Security-Insights-Report.pdf. Acesso em 04 jun. 2020.

SYMANTEC. Norton Cyber Security Insights Report 2016. Global Comparisons. Disponível em: https://www.symantec.com/content/dam/symantec/docs/reports/2016-nortoncyber-security-insights-comparisons-brazil-en.pdf. Acesso em 04 jun. 2020

TAPSCOTT. Don. Plano de ação para uma economia digital. Prosperando na nova era do e-business. São Paulo: Makron Books, 2000.

THE ECONOMIST. Art of lie. Disponível em: https://www.economist.com/news/leaders/21706525-politicians-have-always-lied-does-itmatter-if-they-leave-truth-behind-entirely-art. Acesso em 04 jun. 2020.

WARDLE, Claire. Fake News. It's complicated. First Draft News. Harvard Kennedy School. Shorenstein Center on media, politics and public policy. Disponível em: https://firstdraftnews.com/fake-news-complicated/. Acesso em 04 jun. 2020.

WARDLE, Claire; DERAKSHAN, Hossein. Information disorder: toward and interdisciplinar frameword for reserach and policy making. Council of Europe, October, 2017. Disponível em: https://rm.coe.int/information-disorder-toward-an-interdisciplinaryframework-for-researc/168076277c. Acesso em 05 jun. 2020.

WESTERN SYDNEY UNIVERSITY. What is digital literacy. [2016?]. Disponível em: https://www.westernsydney.edu.au/studysmart/home/digital_literacy/what_is_digital_literacy . Acesso em 05 jun. 2020 